\title{
The welfare impacts of discriminatory price tariffs
}

by

Nikolaos Danias ${ }^{\mathrm{a}}$

J. Kim Swales ${ }^{\mathrm{b}}$

${ }^{a}$ Department of Economics, University of Strathclyde, Glasgow, UK, G4 0QU.

Corresponding author. E-mail: nikolaos.danias@ strath.ac.uk

${ }^{\mathrm{b}}$ Fraser of Allander Institute, Department of Economics, University of Strathclyde, Glasgow, UK, G4 0QU. E-mail:

j.k.swales@strath.ac.uk

January 2018

\begin{abstract}
This paper examines the use of asymmetric tariffs as a regulatory instrument. A monopoly setup is adopted in which the firm sells in two markets but price controls are introduced in just one. The regulator's objective is to increase consumer welfare through this price discriminatory practice, with the firm operating under a profit constraint. We consider cases where consumer welfare in the two markets is weighted both equally and unequally and also cases where the cost of supplying the two retail markets is determined in a monopsonistic input market. The results suggest that in certain situations controlling prices in only one market could be a desirable option from a welfare perspective.
\end{abstract}

Keywords: monopoly; asymmetric regulation; tariffs; welfare

JEL classification: D42, D61, I31, I38, L12, L51

Funding: This research did not receive any specific grant from funding agencies in the public, commercial, or not-for-profit sectors.

Acknowledgements: The authors thank three anonymous referees for valuable comments on a previous version of this paper. 


\section{Motivation}

In the 1980s and 90s the UK energy market was subject to radical deregulation and restructuring. However, subsequent attempts to internalise environmental costs and capital market reconfiguration have led to higher prices, a focus on energy company profits and a continuing concern over affordability (Department for Business, Energy and Industrial Strategy, 2017). Questions regarding the optimal extent and nature of energy markets regulation are politically salient because of the degree of monopoly power suppliers enjoy whilst delivering a commodity considered by consumers and policy makers as a necessity (Joskow, 2005; Joskow and Tirole, 2000, 2006). The trilemma of simultaneously achieving security of supply, affordability and environmental aims poses particular problems (Ang et al., 2015). ${ }^{1}$

In early August Ofgem (2016), Britain's energy regulator, announced proposals to introduce a price cap in just one segment of the market. This was for households using prepayment meters, generally the most vulnerable consumers. Price caps are widely used instruments of regulation (Braeutigam and Panzar, 1993; Brown et al., 2017; Cowan, 2002; Dobbs, 2004; Parker, 1997; Simshauser, 2014) and these proposals have become part of the active debate on the operation of the UK electricity market. They have subsequently been implemented for a subset of customers (Ofgem, 2017).

The present paper models, in a stylised way, the imposition of a price tariff that covers just one segment of the whole market and uses as an example the energy market. The aim is to identify the likely welfare implications of implementing such a policy. Whilst the focus is on energy, this analysis has wider application as selective price controls are adopted in other markets to restrict monopoly power and to affect desirable distributional impacts. For example, in the UK $45 \%$ of rail fares are currently capped

\footnotetext{
${ }^{1}$ In some cases energy policy also becomes an element of industrial policy. For example, the Scottish Government (2015) identifies energy as one of its growth sectors.
} 
(Butcher, 2017), the fees charged in English Universities for undergraduate study is capped, whilst post-graduate fees are not and property companies are also often required to provide a certain proportion of dwellings at controlled (affordable) prices as part of planning permission for larger property developments. Whilst this form of symmetric price regulation is common, its practical effectiveness and accuracy in targeting policy support has been questioned (Simshauser, 2014; Simshauser and Nelson, 2014; Simshauser and Whish-Wilson, 2017).

We investigate this partial application of price controls in a model in which a monopolistic/monopsonistic firm purchases in a unified wholesale market and sells in two retail markets. We focus on the outcomes when one of the retail markets operates under price controls, whereas the other faces no regulation. A key constraint is that the firm bears an obligation to meet the market demand in the controlled market, meaning that quantity rationing is not experienced in that market. ${ }^{2}$ By implementing this asymmetric price control, the regulator effectively imposes price discrimination in the energy retail market which results in indirect income redistribution, facilitated by crosssubsidization between the markets. The analysis proceeds using both algebraic and, more especially, geometric methods.

An important element of the model is that the two markets are not only served by the one firm but they are also potentially inter-connected through their input prices. This is because the output sold to each retail market is supplied using an input purchased in a common wholesale market. Where the wholesale price is an increasing function of output, the two retail markets are interrelated, in that higher levels of activity in one increase costs for the other. Whilst the model uses linear demand and cost functions, it has generality in that it does not otherwise impose specific, or restricted sets of, parameter values.

\footnotetext{
2 The requirement that the firm must meet demand at the tariff means that the regulator effectively simultaneously sets both price and the output level in any market in which a tariff is set.
} 
In this asymmetric regulatory approach, the tariff is only introduced in one segment of the market. But if differential prices are appropriate, then imposing differential tariffs would seem the optimal solution. ${ }^{3}$ However, we are arguing that constraints on the operation of the regulator could make the imposition of price controls in only part of the market a more realistic and sensible option. First, the government might want to retain unrestrained market activity in part of the market for practical or ideological reasons. Second, the government might not have enough political capital to introduce differential tariffs in all sections of the market, especially if this involves explicit crosssubsidisation. These restrictions could constrain the regulator either to impose equal treatment in all sections of the market or introduce regulation in only one section. The welfare implications of these two options are compared in this paper.

The paper presents results which are generally favourable to the imposition of such tariffs. However, it is important to sound a note of caution. To begin, for analytical clarity the model we adopt is extremely stripped down and sparse. We therefore do not deal with the practical problems of introducing, implementing and monitoring the policy (Brown et al., 2017). For example, it is important to be able to separate the markets in an efficient manner, plus there is the question of whether subsidising fuel use is the most effective way of dealing with the difficulties faced by low income households (Felder 2010; Simshauser and Nelson 2014). There is a risk of producing a new batch of fuel poor household not captured and gifted with first round benefits. Also energy policy attempts to achieve a number of goals and in the UK is accompanied by extensive legislation and regulation. In this paper we focus solely on the potential interaction between two issues: the control of market power and affordability. We implicitly treat the instruments to achieve other goals of energy policy, and also other elements of government policy in general, as constraints.

\footnotetext{
${ }^{3}$ The welfare and competition arguments concerning the control of $3^{\text {rd }}$ degree price discrimination are outlined in Armstrong (2008) and Stole (2007). Under certain circumstances allowing $3^{\text {rd }}$ degree profit maximising price discrimination can be welfare enhancing. However, the discussion here involves a slightly different situation where the regulator is imposing a specific form of price control.
} 
Further we do not deal with issues surrounding imperfect information and strategic interaction. In regulating utilities in general, and energy markets in particular, the impact that the decisions of the regulated firms has on the market depends on the regulatory setup and on the way in which the market responds to price incentives (Hviid and Waddams Price, 2012; Waddams Price, 2005). This has implications for actual or potential competition. For example, there has been extensive discussion of the difficulty involved in determining the appropriate treatment of third degree price discrimination in the regulation literature (Armstrong, 2008; Stole, 2007). In the UK this applies particularly to attempts to eliminate geographic price discrimination (Hviid and Waddams Price, 2012). ${ }^{4}$ Kennedy (1994) and Ulph (1996) address the strategic effects of environmental regulation in a different context to the present paper and for the regulation of the UK energy market in general, the work of Littlechild (2014, 2016 and 2017) is particularly relevant.

Section 2 outlines the basic model. As in the rest of the paper, this consists of a monopolist/monopsonist that purchases electricity in the unified wholesale market and sells in two identical retail sectors. In the basic case separate tariffs in the two retail markets are introduced. Section 3 describes the construction of the iso-welfare and isoprofit functions. Section 4 analyses the welfare-maximizing operation of tariffs under the most straightforward conditions. This is where we impose a zero profit constraint, constant wholesale prices and equal welfare weights between retail markets. Section 5 introduces differential welfare weights. Section 6 extends the analysis to investigate the impact of restricting the intervention to imposing a tariff in only one of the retail markets. Section 7 shows the effect of introducing a positive profit constraint. In Section 8 the assumption of a constant wholesale price is relaxed and Section 9 is a short conclusion.

\footnotetext{
${ }^{4}$ We plan to do work in the future explicitly on the impact of price controls on new entry.
} 


\section{The basic model}

We begin by establishing notation and a number of simplifying assumptions. This will allow the construction in Section 3 of iso-profit and iso-welfare functions, which link combinations of tariffs in markets 1 and 2 to given levels of total profit and consumer welfare respectively. These prove to be effective devices for analyzing the options for the regulator.

A monopoly electricity supplier faces two identical retail markets, each characterized by a linear inverse demand function:

$$
p_{i}=a-b q_{i} \quad i=1,2
$$

where $p_{i}$ and $q_{i}$ are the prices and quantities in market $i$, and $a$ and $b$ are parameters which take positive values that do not vary across the two markets. ${ }^{5}$ The value taken by the parameter $a$ is the maximum price that the monopolist can charge in either market and have non-negative sales in that market. Therefore in all the analysis the tariff is never set above $a{ }^{6}$ The parameter $b$ is the (negative) slope of the inverse demand curve. The firm's total cost, $C_{T}$, is made up of a fixed cost, $\Gamma$, and the cost of purchasing electricity in the wholesale market, in which it acts as a monopsonist. The wholesale price of electricity, $p_{W}$, is again assumed to be a linear function of total electricity supply, $q_{T}$. This implies:

$$
C_{T}=\Gamma+p_{W} q_{T}
$$

where

$$
p_{W}=c+d q_{T}
$$

and

\footnotetext{
${ }^{5}$ The basic equations for an analysis where the demand parameters for individual retail markets vary are given in Appendix B.

${ }^{6}$ Of course, the politically-feasible maximum price cap is likely to be lower.
} 


$$
q_{T}=\sum_{i} q_{i}=q_{1}+q_{2}
$$

Again $c$ and $d$ are parameters which take non-negative values; $c$ is the minimum price in the wholesale market that would generate a non-negative supply and $d$ is the slope of the wholesale electricity supply curve. Therefore where $d$ is zero, there is a constant wholesale price for electricity equal to $c$. The general expression for total profits for the company, $\Pi_{T}$, takes the form

$$
\Pi_{T}=\sum_{i} p_{i} q_{i}-p_{W} q_{T}-\Gamma
$$

The unconstrained profit maximizing outcome is derived in Appendix A. However, initially we are concerned with the options for a regulator who can discriminate and differentiate the tariffs, $\bar{p}_{i}$, set in each of the two retail markets. In general it will prove useful to define all the relevant variables as functions of the two price tariffs and the demand and cost parameters. The aim of the regulator is identified as being to maximize the benefit to consumers, but conditional upon a profit constraint on the monopsonist/monopolist retail firm. This constraint might simply be the maintenance of the long-run viability of the firm, linked to the security of supply policy objective. On the other hand, it might be the acceptance of the political influence wielded by the incumbent firm.

We identify the aim of the regulator as maximizing consumer benefits, later defined as consumer surplus, subject to a minimum profit constraint, rather than the more general aim of maximizing welfare for three reasons. First, we judge this to be a better representation of the activities of the regulator and the political constraints that they are likely to encounter. Second because we wish to vary the weights applied to particular income recipients but take as unreasonable an outcome in which negative profits would be the welfare maximizing outcome. Third, this very much simplifies the analysis, with only a small cost in terms of rigour. 
This section simply sets up the model showing the fundamental assumptions and notation. In subsequent sections we analyse the properties of such a model, in particular the impact of intervention to cap prices in the separate retail markets.

\section{Iso-welfare and iso-profit functions}

In this section we identify the general nature of the iso-welfare and iso-profit functions used in this analysis. Defining the total consumer welfare, $S_{T}$, as the weighted sum of the consumer surplus in markets 1 and 2 , for the tariff values $\bar{p}_{1}, \bar{p}_{2} \leq a$ :

$$
S_{T}=\sum_{i=1,2} \omega_{i} S_{i}=\frac{1}{2 b} \sum_{i=1,2} \omega_{i}\left(a-\bar{p}_{i}\right)^{2}
$$

where:

$$
\frac{\partial S_{T}}{\partial \bar{p}_{i}}=\frac{-\omega_{i}\left(a-\bar{p}_{i}\right)}{b} \leq 0
$$

and $\omega_{i}$ is the weight put on the consumer surplus in market $i$.

Consumer welfare is minimized, at the value zero, where $\bar{p}_{1}, \bar{p}_{2}=a$. Where the consumers' welfare is fixed at some positive level, $\bar{S}_{T}$, equation (6) can be interpreted as the associated iso-consumer welfare function which, for convenience, we refer to subsequently as the iso-welfare function. Diagrammatically, in general these functions take the form of segments of an ellipse which is centred on point $\mathrm{A}$, with co-ordinates $(a, a)$ in $\bar{p}_{1}, \bar{p}_{2}$ space. Recall, these segments are restricted to tariff values where $\bar{p}_{1}, \bar{p}_{2} \leq a$. In general the slope of the iso-consumer's welfare function is given as:

$$
\frac{d \bar{p}_{1}}{d \bar{p}_{2}}=\frac{-\partial S_{T} / \partial \bar{p}_{2}}{\partial S_{T} / \partial \bar{p}_{1}}=\frac{-\omega_{2}\left(a-\bar{p}_{2}\right)}{\omega_{1}\left(a-\bar{p}_{1}\right)}
$$


Broadly, the further the tariff values lie below a, the higher the level of consumer welfare. All the iso-welfare functions are vertical where $\bar{p}_{1}=a$ and horizontal where $\bar{p}_{2}=a$.

In order to determine the regulator's optimal choices, we need also to identify the profit constraint. To calculate the monopolist/monopsonist's profit, output in each market is determined by inverting equation (1), average wholesale price is given by equation (3) and the monopolist's profits by equation (5), where in each case tariffs are imposed as the price.

(8) $\Pi_{T}=\frac{\left(b \bar{p}_{1}-b c-d\left(2 a+\bar{p}_{1}+\bar{p}_{2}\right)\right)\left(a-\bar{p}_{1}\right)}{b^{2}}+\frac{\left(b \bar{p}_{2}-b c-d\left(2 a+\bar{p}_{1}+\bar{p}_{2}\right)\right)\left(a-\bar{p}_{2}\right)}{b^{2}}$

This implies that

$$
\frac{\partial \Pi_{T}}{\partial \bar{p}_{i}}=\frac{4 a d+b c+a b-2 d\left(\bar{p}_{1}+\bar{p}_{2}\right)-2 b \bar{p}_{i}}{b^{2}}, \quad \frac{\partial^{2} \Pi_{T}}{\partial\left(\bar{p}_{i}\right)^{2}}=\frac{-2(d+b)}{b^{2}}<0
$$

Using expression (9), the first and second order conditions imply that profits are maximized where both prices take the value $\mathrm{k}$, where:

$$
\bar{p}_{1}=\bar{p}_{2}=k=\frac{4 a d+b c+a b}{2 b+4 d}
$$

This set of tariffs equal the unconstrained monopoly prices where there are two retail markets.

Iso-profit curves are the locus of values for $\bar{p}_{1}$ and $\bar{p}_{2}$ which produce a constant profit for the firm. These are implied by equation (8). In general, they take the form of an ellipse centered around the unconstrained profit-maximising set of market prices.

The general slope of the iso-profit curve, is given as:

$$
\frac{d \bar{p}_{1}}{d \bar{p}_{2}}=\frac{-\partial \Pi_{T} / \partial \bar{p}_{2}}{\partial \Pi_{T} / \partial \bar{p}_{1}}=-\frac{4 a d+b c+a b-2 d\left(\bar{p}_{1}+\bar{p}_{2}\right)-2 b \bar{p}_{2}}{4 a d+b c+a b-2 d\left(\bar{p}_{1}+\bar{p}_{2}\right)-2 b \bar{p}_{1}}
$$


Where the tariffs are equal in both markets, the iso-profit curve will have a slope equal to -1 . This reflects the symmetry in the model. The iso-profit curve is horizontal where $d \bar{p}_{1} / d \bar{p}_{2}=0$. From equation (11) this requires that $\partial \Pi_{T} / \partial \bar{p}_{2}=0$ which occurs where

$$
4 a d+b c+a b-2 d\left(\bar{p}_{1}+\bar{p}_{2}\right)-2 b \bar{p}_{2}=0 .
$$

Rearranging equation (12) identifies the value of $\bar{p}_{2}$ that produces the highest profits, given a tariff $\bar{p}_{1}$.

$$
\bar{p}_{2}=\frac{4 a d+b c+a b}{2(b+d)}-\frac{d}{b+d} \bar{p}_{1}
$$

Equation (13) is useful for constructing iso-profits curves. However, it also serves as a reaction function for the firm where only one price is capped. Replacing the tariff $\bar{p}_{2}$ with the freely chosen price, $p_{2}$, equation (13) shows the profit-maximising, therefore freely chosen, price in market 2 where the regulator imposes a fixed tariff in market 1 .

Initially the no-fixed-cost zero iso-profit case is used as a benchmark. Where the markets are treated identically, so that the tariff imposed in both markets is the same, zero profits occur where: $\bar{p}_{1}, \bar{p}_{2}=a$ or $\frac{b c+2 a d}{b+2 d}$. Where both tariffs equal $a$, there is zero demand, therefore zero profits. Again note that $a$ is an effective upper bound for the price tariff, as higher values imply negative demand. Where the two tariffs take the lower value, $\frac{b c+2 a d}{b+2 d}$, which is subsequently denoted as $\mathrm{z}$, the tariff is set at the wholesale price. Note that with identical markets the identical profit maximizing tariff value, $\mathrm{k}$, given in equation (10), is the mean value between the two zero profit values, $\mathrm{a}$ and $\mathrm{z}$.

In this section therefore we have identified the generalized iso-welfare and iso-profit functions implied by the model set out in Section 2. In subsequent sections we introduce and explore the results for specific circumstances represented by the imposition of particular sets of parameter values. 
4 Iso-welfare function with equal consumption weights and the zero profits constraint with fixed wholesale prices

Figure 1: Maximum iso-welfare function with equal weights and the zero profit constraint with constant wholesale prices

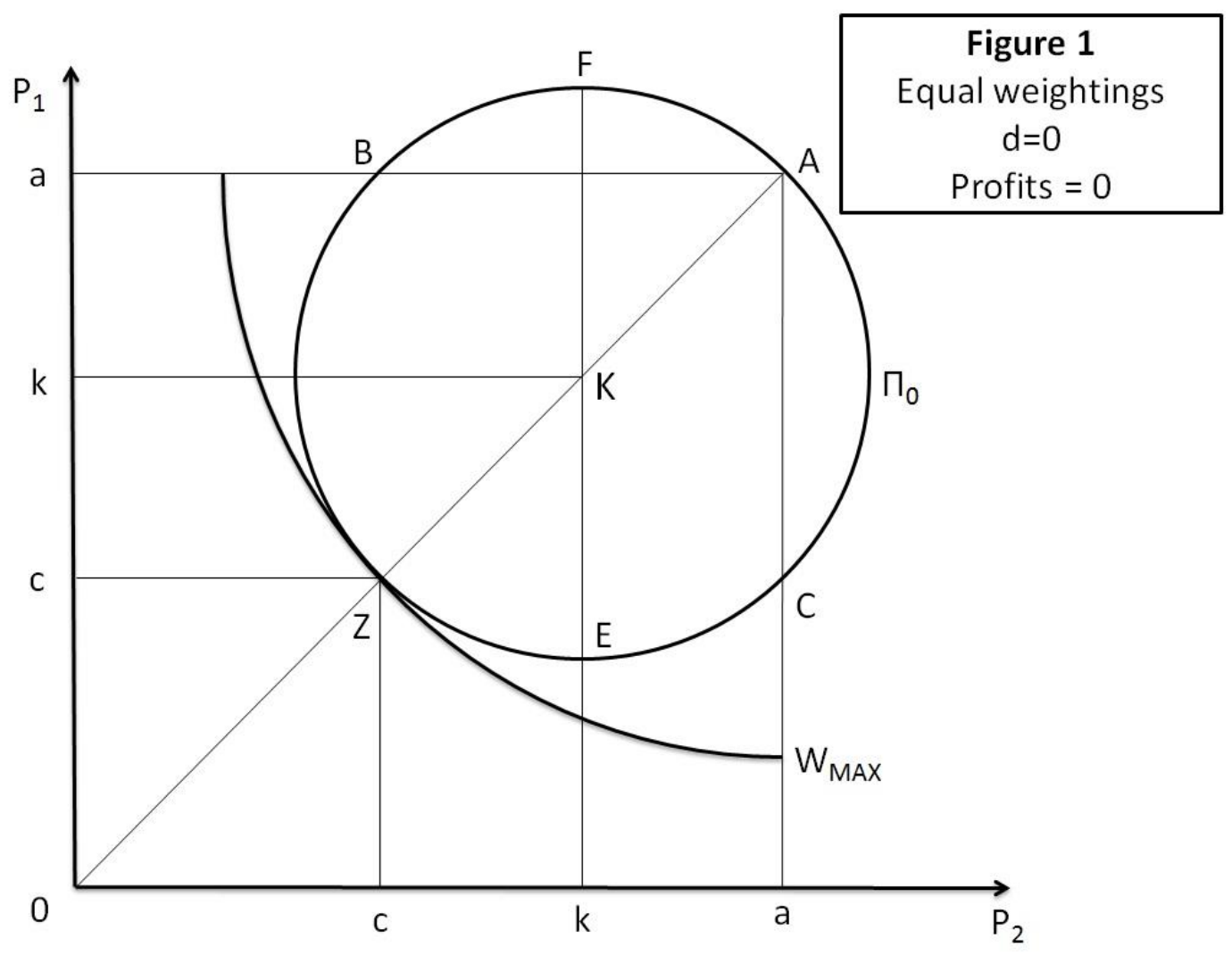

It is useful initially to take the special case where the wholesale price is fixed at the level $\mathrm{c}$ and is invariant to the output level, so that $\mathrm{d}=0$, and the welfare weights are both set equal to unity, so that $\omega_{1}=\omega_{2}=1$. This allows us to specify precisely the isowelfare and iso-profit curves in a tractable manner and establish some benchmark results. These curves are illustrated as shown in Figure 1. 
We start with the iso-welfare function. From equation (6), if consumers in each market are given a weight of unity, the iso-consumer surplus curve, where the two price tariffs are $\bar{p}_{1}$ and $\bar{p}_{2}$, is represented by the formula:

$$
\bar{S}_{T}=\frac{1}{2 b}\left[\left(a-\bar{p}_{1}\right)^{2}+\left(a-\bar{p}_{2}\right)^{2}\right]
$$

Expression (14) is the equation of a circle in whose center is point $A$, though remember that this representation is only valid for values of $\bar{p}_{i} \leq a$. If $R$ is the radius of that circle, equation (14) can be replaced by:

$$
\bar{S}_{T}=\frac{R^{2}}{2 b}
$$

The iso-welfare functions can then be represented by a set of quarter circles in $\bar{p}_{1}, \bar{p}_{2}$ space whose centers are at $\mathrm{A}$. $\mathrm{W}_{\mathrm{MAX}}$ is one such iso-welfare function and the further from $\mathrm{A}$ the iso-welfare function is, the higher is the consumer welfare. From equation (7), the slope of the function equals -1 where $\bar{p}_{1}=\bar{p}_{2}$, that is to say on the 45 degree line through the origin. The iso-welfare curves are vertical and horizontal at their end points, where one of the relevant prices takes its maximum value, $a$.

For the iso-profits curve, substituting $\mathrm{d}=0$ into equation (8) gives the total profits as:

$$
\Pi_{T}=\frac{\left(\bar{p}_{1}-c\right)\left(a-\bar{p}_{1}\right)}{b}+\frac{\left(\bar{p}_{2}-c\right)\left(a-\bar{p}_{2}\right)}{b}
$$

Equation (16) can be reformulated as:

$$
\left[\bar{p}_{1}-\left[\frac{a+c}{2}\right]\right]^{2}+\left[\bar{p}_{2}-\left[\frac{a+c}{2}\right]\right]^{2}=\frac{(a-c)^{2}}{2}-b \bar{\Pi}_{T}
$$

This is the equation for the iso-profit curve where profits equal $\bar{\Pi}_{T}$. In this specific case, that is where wholesale price is constant, the iso-profit curve is represented as a circle whose center is $\frac{a+c}{2}$ and whose radius, $\mathrm{r}$, is $\sqrt{\frac{(a-c)^{2}}{2}-b \bar{\Pi}_{T}}$. 
Figure 1 shows the zero iso-profit curve $\Pi_{0}$. Imposing equal tariffs, so that $\bar{p}_{1}=\bar{p}_{2}$, the lowest tariff values on this curve, which we call more generally $Z$, is equal to $(c, c)$. From equation (10) the profit maximizing tariffs are: $\left(\frac{a+c}{2}, \frac{a+c}{2}\right)$, and this point we label, again more generally as $\mathrm{K}$, with co-ordinates $(\mathrm{k}, \mathrm{k})$. Given the constraint that output cannot take negative values, the zero iso-profit curve comprises an isolated point, $A$, and the arc $B Z C$ where at points $\mathrm{A}$ and $\mathrm{Z}$, the tariffs in both markets take the value a and c respectively. In this case, the segment BZC comprises one half of a circle whose center is the profit maximizing tariffs $\left(\frac{a+c}{2}, \frac{a+c}{2}\right)$. This zero iso-profit curve goes through the points $(c, c),(c, a)$ and $(a, c)$ and from equation (17) has a radius equal to $\frac{a-c}{\sqrt{2}}$.

One key element of the analysis is the locus of tariff values where the iso-profit curves are horizontal or vertical. Using equation (13) and substituting $\mathrm{d}=0$ reveals that the tariff in markets 2 which maximizes profits, given a specific tariff in market 1 is $\frac{a+c}{2}$ . This is at point E. This relationship is symmetric, so the iso-profit curve is vertical where $\bar{p}_{1}=\frac{a+c}{2}$ and horizontal where $\bar{p}_{2}=\frac{a+c}{2}$. However, a second interpretation is that these points show the minimum values of each tariff that will support a given profit level. The minimum level of $\bar{p}_{1}$ is shown where the iso-profit curve is horizontal, the minimum level of $\bar{p}_{2}$ where it is vertical.

Using equations (6) and (8) as the determinants of consumer surplus and profits, maximizing the consumer surplus, subject to a profit constraint requires:

$$
\frac{\partial S_{T} / \partial \bar{p}_{1}}{\partial S_{T} / \partial \bar{p}_{2}}=\frac{\partial \Pi_{T} / \partial \bar{p}_{1}}{\partial \Pi_{T} / \partial \bar{p}_{2}}
$$


In the symmetric case, where the consumption weights are equal, partially differentiating the expressions given in equations (6) and (16) for the consumer surplus and total profits and substituting the results into equation (18) produces the symmetrical outcome that the consumer surplus is maximized where the tariff in both markets is the same. Using this and the zero profit requirement, together with equation (16) gives the result that $\bar{p}_{1}, \bar{p}_{2}=c .{ }^{7}$ The welfare-maximising regulator in this case should impose a tariff equal to $c$ in each market and the welfare maximizing point is at $Z$. Figure 1 shows that the zero iso-profit curve as the half circle, center $K$, which goes through $Z$. If the welfare of consumers in each market is given the same weight, the highest attainable consumer iso-welfare function, consistent with non-negative profits, is the quarter circle, center $A$, which is just tangent to the zero-profit curve at $Z$. This is the optimal position in this case.

This section constructed the iso-welfare and iso-profit curves where there is a fixed wholesale price, a zero profit constraint and where the consumption weights in each retail market are equal. In subsequent sections we consider the imposition of a tariff in market 1 , leaving the firm able to set an unregulated profit maximising price in market 2. We also relax a number of the assumptions concerning the parameter values and weights.

\footnotetext{
${ }^{7}$ With no discretionary weights (that is, setting all weights to unity) the standard first order conditions for maximizing welfare are that:

$$
\frac{\partial W_{i}^{F}}{\partial \bar{p}_{i}^{F}}=\frac{\partial S_{i}^{F}}{\partial \bar{p}_{i}^{F}}+\frac{\partial P_{T}^{F}}{\partial \bar{p}_{i}^{F}}+\frac{\partial \Pi_{T}^{F}}{\partial \bar{p}_{i}^{F}}=0 \quad \forall_{i}
$$

In this equation $\mathrm{P}$ is the producer surplus of the wholesale firms. Setting $d=0$ implies that the producer surplus is zero, so that in this case, this means maximizing conventional welfare with a zero profits lower bound is equivalent to maximizing consumer surplus with a zero profits constraint. However, here $d>0$, changes in output will affect producer surplus. This means that maximizing consumer surplus does not typically maximize standard welfare measures, though marginal benefits to wholesalers will only occur at the cost of reduced benefits to consumers.
} 
5. Model with un-equal consumer weights $\left(\omega_{1}>\omega_{2}\right)$.

Varying the consumer welfare weights across the two retail markets changes the optimal outcome if the regulator can set a tariff in both markets. Increasing the weight on market 1 shifts the consumer iso-welfare function so that it is tangent to the zero isoprofit curve along the segment $Z E$. This is illustrated in Figure 2. The iso-welfare curve $W_{1}$ that passes through point $Z$ is no longer tangent to the zero iso-profit curve. The highest (weighted) consumer surplus is now found at point $\mathrm{H}$ on the iso-welfare curve $W_{2}$. Increasing the weight on the consumers in market 1 will shift the optimal set of tariffs towards E, meaning a lower value for $\bar{p}_{1}$ and a higher value for $\bar{p}_{2}$.

The most extreme case is where the welfare of consumers in market two is given zero weight by the regulator. In this case, the iso-welfare curves become straight horizontal lines, with lower lines producing higher consumer welfare. This would lead to an optimal outcome given by point $\mathrm{E}$. The monopoly price is still charged in market 2 but the profits generated in that market are wholly used to subsidise the consumers in market 1 .

The segment $Z E$ in both Figures 1 and 2 might include a range where the tariff in market 1 is negative. Take, for example, the situation where there are no wholesale cost so that $c=0$. In this case, all the points on the zero iso-profit line, apart from points $A$ and $Z$, have a negative price tariff in one of the markets. In principle, the existence of negative prices is not problematic (although negative output clearly is). Negative prices could represent the firm paying subsidies to consumers in one market, rather than charging a

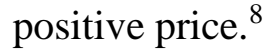

\footnotetext{
${ }^{8}$ Though not an exactly comparable situation, senior citizens travel free on all Scottish buses and coaches. For some long journeys this includes also free coffee and snacks. These free refreshments might be thought of a negative price to use the public transport. Also some educational establishments will provide bursaries, rather than charge fees, for low-income pupils.
} 
Figure 2: Maximum iso-welfare function with consumer weights in favour of market 1 and the zero profit constraint with constant wholesale prices

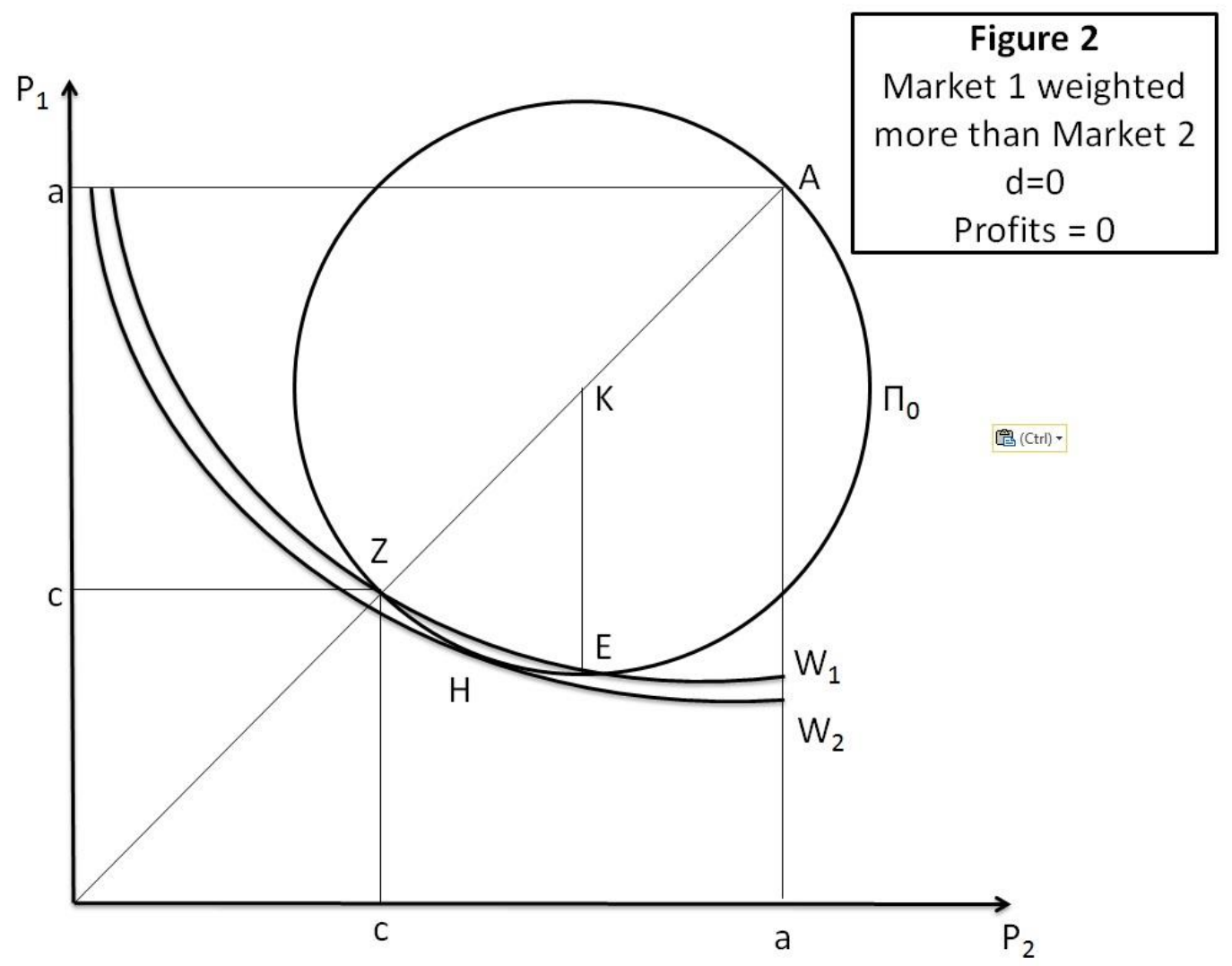

In this section we have shown that the analysis can accommodate differential weighting of consumer welfare. This would, in itself, suggest that within the restricted assumptions of this approach an optimal position would be for the regulator to set different tariffs in the different markets.

\section{A tariff in only one of the two markets, zero profit constraint, constant wholesale prices}

Up to this point we have essentially outlined a model in which the regulator sets tariffs in each of the two retail markets. However, the primary focus of the paper is the analysis of situations where, for some reason, the extent to which the separate markets can be regulated is restricted and, in particular, the extreme case where tariffs can only be set 
in one of the two markets. Regulators might face political, ideological or practical constraints in imposing tariffs in all segments of the retail market. Our concern, which will make up the remainder of the paper, is to quantify the size of the loss in efficiency that such a constraint would imply, compared to the outcome where tariffs are optimally set in both markets.

The formal problem facing the regulator is to set a tariff in market 1 so as to maximize total consumer surplus, subject to the monopolist setting the price in market 2 and being subject to a profit constraint. In principle, the price set in market 2 that maximizes the firm's total profits depends on the tariff set in market 1 , in the form of the reaction function. This constraint is given by equation (13). The regulator's problem can be expressed as finding the tariff to apply in market 1 which:

$$
\operatorname{Max}_{T}=\frac{1}{2 b}\left[\left(a-\bar{p}_{1}\right)^{2}+\left(a-p_{2}\right)^{2}\right]
$$

subject to

$$
p_{2}=\frac{4 a d+b c+a b}{2(b+d)}-\frac{d}{b+d} \bar{p}_{1}
$$

and

$$
\bar{\Pi}_{T} \geq 0
$$

Where $d=0$, the profit maximizing price in market 2 is independent of the tariff in market 1 and from the discussion in Section 4 equals $\frac{a+c}{2}$. Essentially, the reaction function is a vertical straight line KE in Figures 1 and 2. Consumer welfare is negatively related to the price in market 1 , so that welfare is maximized at E. Using equation (17) this is where $\bar{p}_{1}=\frac{(a-c)(1+\sqrt{2})}{2}$. In the remainder of this section we compare the welfare benefits that accrue from imposing a uniform tariff across both markets to a tariff applied in only one market. 
6.1 Model with equal consumer weights of unity $\left(\omega_{1}=\omega_{2}=1\right)$.

Using Pythagoras's theorem, the iso-welfare function that passes through the point $\mathrm{K}$ in Figures 1 and 2 that maximizes the monopoly profit has a radius $\sqrt{ } 2 f$, where $f$ is half the distance between the maximum price $a$ and the wholesale price, $c$, so that:

$$
f=\frac{a-c}{2}
$$

From equation (12) the associated consumer surplus is therefore $\frac{f^{2}}{b}$. With optimal regulation, given the zero profit constraint, tariffs are set at $Z$. The radius of the isowelfare function passing through that point is $2 \sqrt{ } 2 f$, so that the associated consumer surplus is $\frac{4 f^{2}}{b}$. Moving to the optimal regulation improves consumer welfare, as measured by the consumer surplus, by a factor of 4 . However, if the regulator is restricted to setting a tariff in only one market, how does this affect the resulting welfare?

With only one tariff in operation, consumer welfare is optimized at point $E$, and with equal consumer weights in each market the radius of the iso-welfare function that goes through this point is given as:

$$
R^{2}=(\sqrt{2} f+f)^{2}+f^{2}=2(2+\sqrt{2}) f^{2}
$$

Substituting this result into equation (15) gives a consumers surplus of $\frac{(2+\sqrt{2}) f^{2}}{b}$. This value, expressed as a ratio of the optimal welfare is $\frac{2+\sqrt{2}}{4}=0.85$. Alternatively, if the changes in welfare, rather than the absolute values, are compared the ratio is $\frac{1+\sqrt{2}}{3}=0.80$. Therefore although there is a loss in effectiveness in only being able to target one market, the increase in welfare is only reduced by $20 \%$ and the consumer surplus in the market not receiving the tariff is unchanged. 


\subsection{Model with un-equal consumer weights $\left(\omega_{1}>\omega_{2}\right)$}

In the case where $d=0$, if the regulator can decide which market to target, $20 \%$ represents the maximum lost potential welfare. Where greater weight is placed on the benefits to one set of consumers, this will reduce the resulting loss in effectiveness, as against a situation where the same tariff is applied to both sets of consumers. ${ }^{9}$ Where the weights differ markedly, the regulator might prefer imposing a tariff in only one market rather than a uniform tariff in both. The analysis can be used to find the relative weights that have to be placed on the consumer surplus in the two markets for this to occur. ${ }^{10}$

Where the two markets are weighted unequally, the maximum consumer surplus where both tariffs are constrained to take the same value is $f^{2}\left[\frac{2 \omega_{1}+2 \omega_{2}}{b}\right]$. Where the tariff can only apply in market 1 , the maximum consumer surplus is $f^{2}\left[\frac{\omega_{1}(3+2 \sqrt{2})+\omega_{2}}{2 b}\right]$. Therefore if the regulator is faced with this choice, the optimal decision would be to apply the tariff only in market 1 if:

$$
\frac{\omega_{1}(3+2 \sqrt{2})+\omega_{2}}{2 b}>\frac{2 \omega_{1}+2 \omega_{2}}{b} \rightarrow \frac{\omega_{1}}{\omega_{2}}>\frac{3}{2 \sqrt{2}-1}=1.64
$$

Therefore as long as consumer surplus in market 1 is weighted more than $64 \%$ higher than in market 2 , it is better to place an optimal tariff only in market 1 than have to impose equal tariffs in both markets. It is of interest to note that the UK Government

\footnotetext{
${ }^{9}$ Recall that the differential weights do not affect the optimal unified tariffs that should be set in both markets or the single tariff set in just one. The differential weights simply change the valuation of the resulting outcomes.

${ }^{10}$ It could be the case that other aspects of energy policy could also benefit from segmenting the market. For example, emissions from some uses might have a higher negative value than others. This segmentation might or might not correspond with affordability. Further, it is negatively linked to the quantity of energy used rather than positively related to consumer surplus. Clearly this would complicate the analysis and is beyond the scope of this paper.
} 
suggests weights for different additions to income across different income quintiles (HM Treasury, 2003, Annex 5). ${ }^{11}$ The average weight for people in the lowest two quintiles is 1.65 , which is more than double the average value for those in the top three quintiles (0.72). Under these weights it would be more efficient to set a tariff in a market serving the lowest two quintile of the income distribution as against a uniform tariff that applied across the market serving the whole of the population.

In this section we compare the outcome from an optimal uniform tariff across both markets and an optimal single tariff imposed in just one. Where consumer welfare benefits in one market are weighted more highly than in the other, the single tariff can be optimal. However, this is shown for a restricted model where a zero profits constraint is imposed and in which the two markets are not directly linked through endogenous price changes in the wholesale market. In the subsequent sections we relax these assumptions.

\section{A tariff in only one of the two markets, positive profit constraint}

Up to now we have only constrained profits to be non-negative. However, if fixed costs are positive, so that $\Gamma>0$, or if the company has some kind of power with which it can push back against the regulator, the profit constraint will be positive. We would expect some implicit profit constraint to be determined by bargaining between the regulator and the incumbent. If this profit level is set too low, there might be a number of consequences. There might be difficulties with financing new investment, attempts to evade the requirement to meet the total demand at the regulated price and potential bankruptcy if there are unexpected variations in costs or demand. We show that with a positive profits constraint, the relative disadvantage of a tariff limited to one market is reduced, as is the ratio of the consumer weights required before the single tariff becomes the desired option.

\footnotetext{
${ }^{11}$ The midpoint values for weights for net changes in income in the five quintiles, starting from the lowest income, are 1.95, 1.35, 0.95, 0.75, and 0.45 respectively (HM Treasury, 2003, p. 94).
} 
Figure 3: Maximum iso-welfare function with equal weights and a positive profit constraint with constant wholesale prices

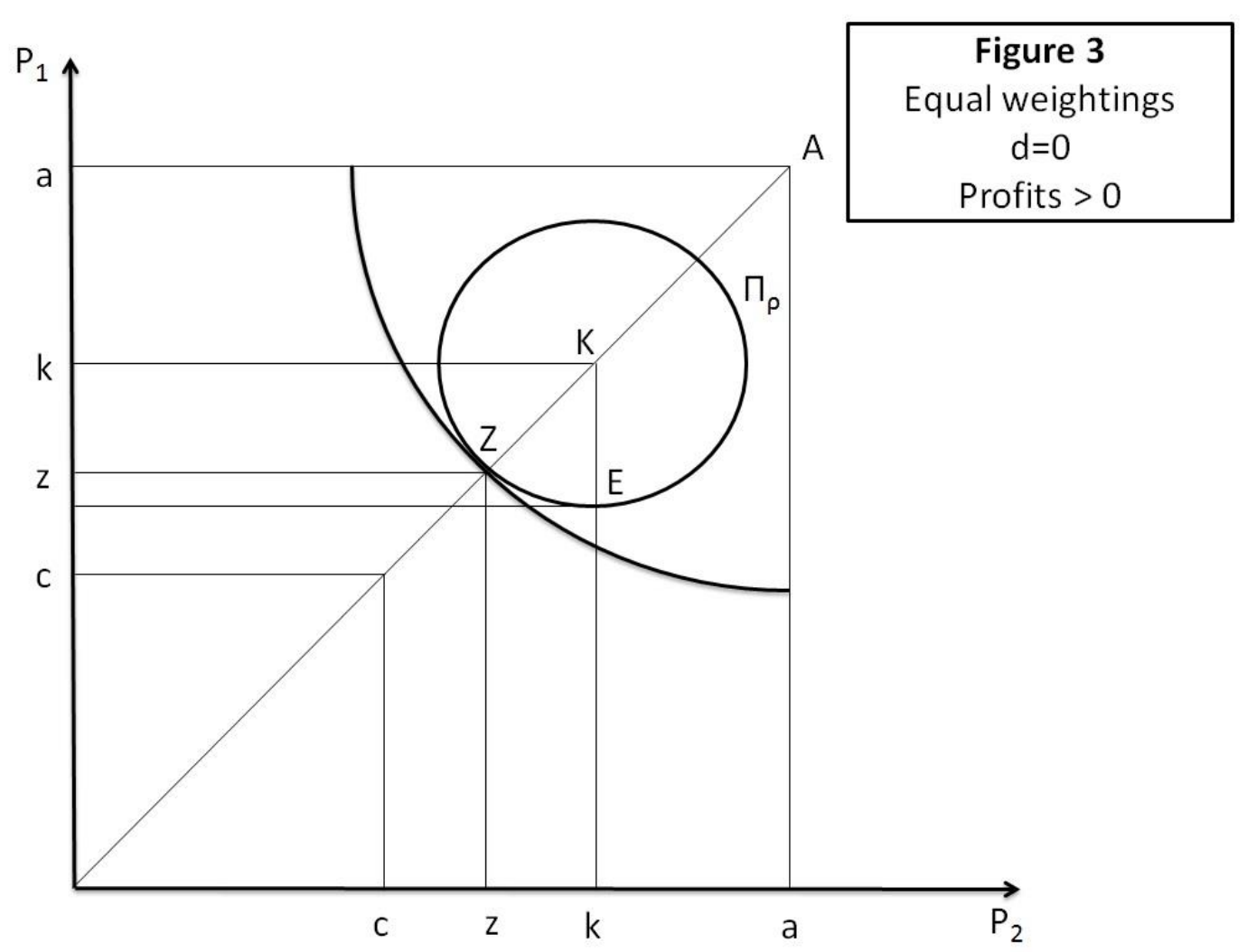

The maximum, unregulated, profits, $\Pi_{M A X}$, are determined by substituting the value $\bar{p}_{1}^{F}, \bar{p}_{2}^{F}=\frac{a+c}{2}$ into equation (17). This gives the result:

(22) $\quad \Pi_{M A X}=\frac{2}{b}\left[\frac{a-c}{2}\right]^{2}=\frac{2 f^{2}}{b}$

Using equation (22), it is convenient to express the actual profit constraint, $\bar{\Pi}_{T}$, as a proportion, $\bar{\rho}$, of the maximum value, so that:

(23) $\quad \bar{\Pi}_{T}=\bar{\rho} \Pi_{M A X}=\frac{2 \bar{\rho} f^{2}}{b}$ 
where $1 \geq \bar{\rho} \geq 0$. Substituting this into the expression associated with equation (17) for the radius of the iso-profit curve, $r$, gives the result that ${ }^{12}$

$$
r^{2}=2(1-\bar{\rho}) f^{2} \rightarrow r=\sqrt{2(1-\bar{\rho})} f
$$

Therefore if $\bar{\rho}=0$ we have the zero profit case where $r=\sqrt{ } 2 f$, whereas $\bar{\rho}=1$ produces the profit maximizing case where $r=0$. For values of $\bar{\rho}$ between 1 and 0 , the radius of the iso-profit line lies between 0 and $\sqrt{ } 2 f$. As the profit constraint increases the circular iso-profit curve moves closer to the profit-maximising point $\mathrm{K}$. Note that now the profit constraint no longer goes through point $A$ (representing prices $a, a$ ). Also the point $Z$ which minimizes prices in both markets, consistent with the profits constraint and price equality, now represents prices greater than $c$.

We can use equations (15) and (24) to calculate the new maximum welfare where there is a positive profit identified by $\bar{\rho}$. The maximum value of $R$ is now $[\sqrt{2}+\sqrt{2(1-\bar{\rho})}] f$ . The maximum consumer surplus, where consumption is given an equal weight of unity in both markets is:

$$
\bar{S}_{T}=\frac{[\sqrt{2}+\sqrt{2(1-\bar{\rho})}]^{2} f^{2}}{2 b}=\frac{[2-\bar{\rho}+2 \sqrt{(1-\bar{\rho})}] f^{2}}{b} \text { where } \frac{\partial \bar{S}_{T}^{F}}{\partial \bar{\rho}}<0 .
$$

Not surprisingly there is a negative relationship between the level of the profit constraint and the maximum consumer surplus.

We can similarly calculate the implication of introducing the tariff in only one market and imposing the profit constraint. Again if the tariff is imposed in market 1, the output in market 2 remains at the monopoly level and the excess profits in that market subsidise output in market 1 . The maximum consumer surplus (both markets with a unitary weight) is now:

\footnotetext{
${ }^{12}$ Recall that the upper-case, $R$, is the radius of the iso-welfare function and the lower case, $r$, the radius of the iso-profit function.
} 
(26) $\bar{S}_{T}^{F}=\frac{\left[1+[1+\sqrt{2(1-\bar{\rho})}]^{2}\right] f^{2}}{2 b}=\frac{[2-\bar{\rho}+\sqrt{2} \sqrt{(1-\bar{\rho})}] f^{2}}{b}$ with again $\frac{\partial \bar{S}_{T}^{F}}{\partial \bar{\rho}}<0$.

Similarly, the ratio, $\Omega$, of the consumer welfare where one tariff is imposed, as against a common tariff in both markets, is:

$$
\Omega=\frac{2-\bar{\rho}+\sqrt{2} \sqrt{(1-\bar{\rho})}}{2-\bar{\rho}+2 \sqrt{(1-\bar{\rho})}}<1
$$

However, $\frac{\partial \Omega}{\partial \bar{\rho}}>0$, so that this ratio gets higher, and approaches unity as the value of $\bar{\rho}$ approaches 1 . That is to say, the proportionate loss in welfare in an optimal single market tariff, as against a common tariff in both markets falls as the profit constraint tightens.

Where the profit constraint is positive, there is an increase in welfare where the weights for market 1 and 2 are such that:

$$
\begin{aligned}
\frac{\omega_{1}[3-2 \bar{\rho}+2 \sqrt{2} \sqrt{(1-\bar{\rho})}] f^{2}}{2 b}+\frac{\omega_{2} f^{2}}{2 b}> \\
\frac{\omega_{1}[2-\bar{\rho}+2 \sqrt{(1-\bar{\rho})}] f^{2}}{2 b}+\frac{\omega_{2}[2-\bar{\rho}+2 \sqrt{(1-\bar{\rho})}] f^{2}}{2 b}
\end{aligned}
$$

which implies $\frac{\omega_{1}}{\omega_{2}}>\frac{[1-\bar{\rho}+\sqrt{2} \sqrt{(1-\bar{\rho})}]}{[1-\bar{\rho}+2(\sqrt{2}-1) \sqrt{(1-\bar{\rho})}]}$.

This means that, for example, if $\rho$ equals 0.5 , then if $\frac{\omega_{1}}{\omega_{2}}>1.38$, then it is better for the regulator to impose a tariff solely in market 1 , rather than impose a common tariff in both markets. Again, given the recommended weights from HM Treasury (2003), any tariff that can exclusively target lowest three income quintiles would have a clear weighting above 1.4 . 
This section shows that where there is a positive profits constraint, the unweighted welfare differences between a uniform and elective tariff are reduced and targeting the market with the higher welfare weights is more likely to be the preferred policy.

\section{The introduction of a tariff in market 1 where the wholesale price increases with output $(d>0)$}

Sections 6 and 7 analyse pure cross subsidisation, where the positive profits made in the unregulated retail market 2 are used to subsidise consumers in the regulated market 1. Whilst market 2 consumers receive no benefit from the regulation, neither do they experience any detrimental impact. However, in this section, where we introduce a positively sloping wholesale supply curve, the analysis becomes more complex because the two markets become inter-related on the cost side.

The adoption of a positive value for the wholesale supply parameter $d$ has a number of important implications. Consider the zero iso-profit curve and compare it to the circular curve, where $d=0$, discussed in detail in Section 4. The iso-profit curve where $d>0$ is illustrated in Figure 4. 
Figure 4: The zero profit constraint with increasing wholesale prices

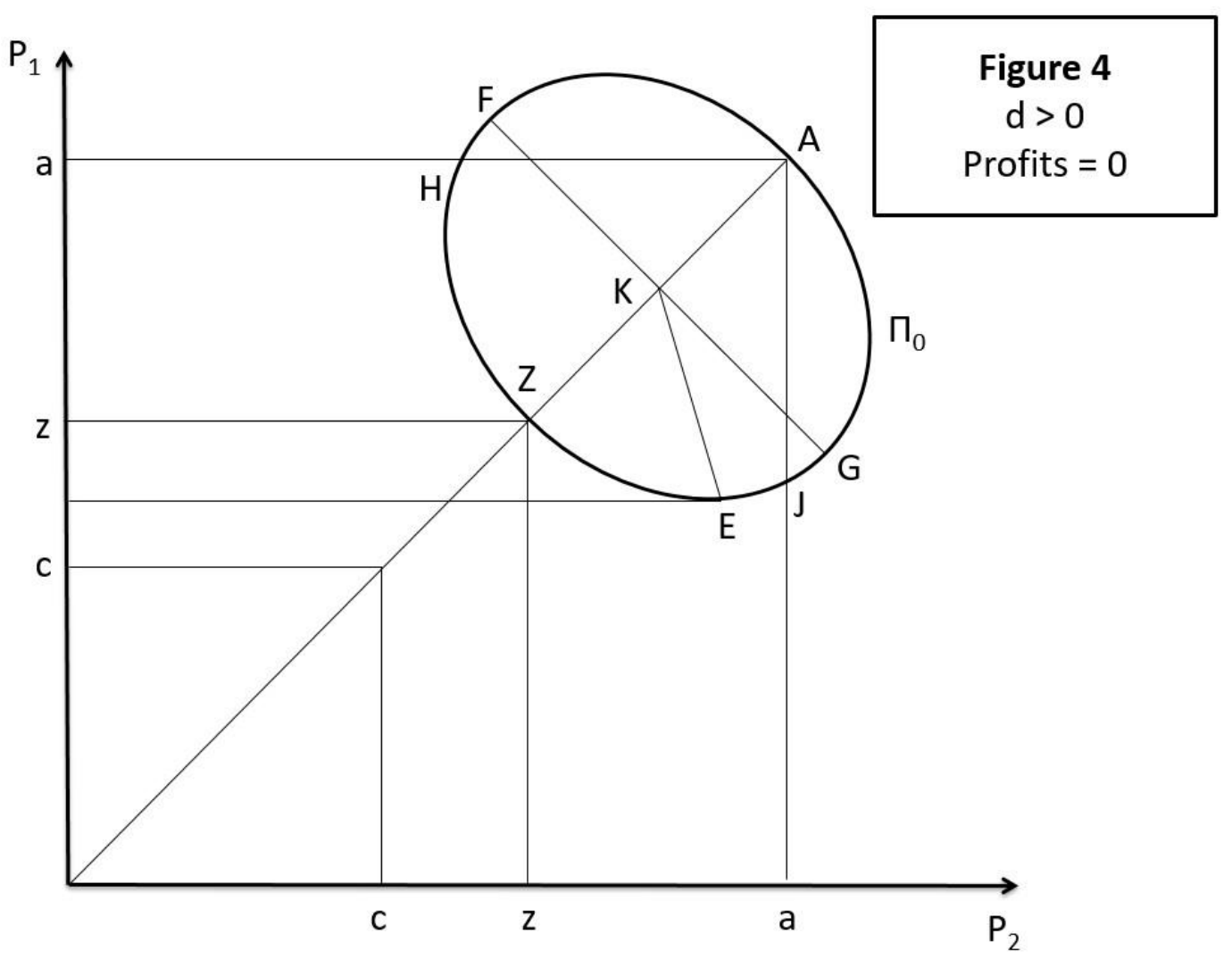

The zero iso-profit curve now comprises the point $A(a, a)$ and the segment of the elipse HZJ where $\bar{p}_{1}, \bar{p}_{2} \leq a$. The point $Z(z, z)$, where wholesale cost equals retail price, has moved further up the 45 degree line drawn through the origin: that is to say, $\mathrm{z}>\mathrm{c}$. The unconstrained profit maximizing point, $K(k, k)$, is still at the mid-point between $A$ and $Z$. The zero iso-profit curve is symmetric around the two perpendicular axes that have negative and positive 45 degree slopes and pass through the point $K$. The width on the 45 degree line through the origin, $A Z$, is now shorter than the distance along the other axis, $F G$. This is also verified by the fact that the points $(z, a)$ and $(a, z)$ are no longer on the zero iso-profit curve, but generate positive profits.

The general slope of the iso-profit curve is given in equation (11). Where the tariffs are equal in both markets, the iso-profit curve will have a slope equal to -1 . This reflects the symmetry in the model. The iso-profit curve is horizontal where $d \bar{p}_{1} / d p_{2}=0$. Equation (13) in Section 3 gives the equation for the value of $p_{2}$ where this would hold, for any specific value of $\bar{p}_{1}$. As we noted there, this can be interpreted as a reaction 
function: it is the price set in the unregulated market 2 that will be the best response to the regulator setting a specific tariff, $\bar{p}_{1}$, in market 1 .

In Section 6, we show that in the special case where $d=0$, this reaction function reduces to $p_{2}=\frac{a+c}{2}$, a vertical line. But in the general case, where the wholesale price rises as total output increases, this reaction function has a negative slope equal to $-\frac{b+d}{d}$. This is shown as $K E$ in Figure 4 for values of $\bar{p}_{1} \leq k$. This implies that if the tariff in market 1 falls by 1 unit, the profit maximizing price in market 2 will increase by $\frac{d}{b+d} \leq 1$. There is now a clearer trade-off between the prices consumers face in the separate markets. A tariff imposed solely in market 1 in a previously unregulated system means that the consumer surplus in market 2 now falls as the consumer surplus in market 1 rises.

Fully differentiating equation (6) with respect to $\bar{p}_{1} \leq k$ shows the impact of varying the tariff in market 1 on total consumer surplus:

$$
\begin{aligned}
& \frac{d \bar{S}_{T}}{d \bar{p}_{1}}=\frac{\partial \bar{S}_{T}}{\partial \bar{p}_{1}}+\frac{\partial \bar{S}_{T}}{\partial p_{2}} \frac{d p_{2}}{d \bar{p}_{1}}=-\frac{1}{b}\left[\omega_{1}\left(a-\bar{p}_{1}\right)-\frac{d}{b+d} \omega_{2}\left(a-p_{2}\right)\right] \\
& \text { where } \frac{d \bar{S}_{T}}{d \bar{p}_{1}}<0 \quad \text { iff } \quad \omega_{1}(b+d)\left(a-\bar{p}_{1}\right)>\omega_{2} d\left(a-p_{2}\right)
\end{aligned}
$$

Given that this inequality always holds, by construction, the welfare maximizing decision for the regulator is to reduce the tariff in market 1 , subject to the profit constraint.

Actually the solution for the minimum market tariff where a particular profits constraint is imposed is conceptually straightforward but complex in practice, generating terms which do not yield easily to intuition. One potential issue is whether the restriction that 
the price in market 2 cannot rise above the value $a$ acts as a constraint in this case. Essentially this is asking the question: can the regulator set a tariff in market 1 such that the firm's profit-maximising response would be to produce zero output in market 2 yet still make positive profits?

Using equation (13), the tariff in market 1 at which the profit maximising price in market 2 equals a, so that the demand in that market falls to zero, is given by:

$$
\bar{p}_{1}=a-\frac{b(a-c)}{2 d}
$$

From equation (1) this gives an output in market 1 of :

$$
q_{1}=\frac{(a-c)}{2 d}
$$

Substituting (30) and (31) into equations (3) and (5) produces the profits figure:

$$
\Pi_{T}=\Pi_{1}=(d-b)\left[\frac{a-c}{2 d}\right]^{2}>0 \quad \text { iff } \quad d>b
$$

The condition for positive profits is therefore simply that the absolute slope of the supply function be greater than the slope of the demand function. If this expression holds, the minimum tariff consistent with non-negative profits in market 1 would be where the tariff in market 1 just equals the wholesale price. This implies that:

$$
\bar{p}_{1}=c+d \bar{q}_{1}=c+d\left[\frac{a-\bar{p}_{1}}{b}\right]=\frac{a d+b c}{b+d}
$$

Therefore, where $d \geq b$, we can define a tariff range for market 1 where the profit maximising output for market 2 is zero. This range is given by:

$$
a-\frac{b(a-c)}{2 d} \geq \bar{p}_{1} \geq \frac{a d+b c}{b+d}
$$

If the tariff is set in this range, the firm will only operate in the regulated market. 
It is interesting to consider the special case where $b=d$. In this case the zero iso-profit is horizontal at $E$ where it cuts the vertical line through $A$. This implies that the minimum price tariff in market 1 consistent with non-negative profits just leads to output in market 2 becoming unprofitable. This is illustrated in Figure 5. In this case, from equation (13) the line $K E$ has a slope equals -2 .

Figure 5: Maximum iso-welfare function with equal weights and the zero profit constraint with increasing wholesale prices and the slope of the retail demand curve equal to the slope of the wholesale supply curve.

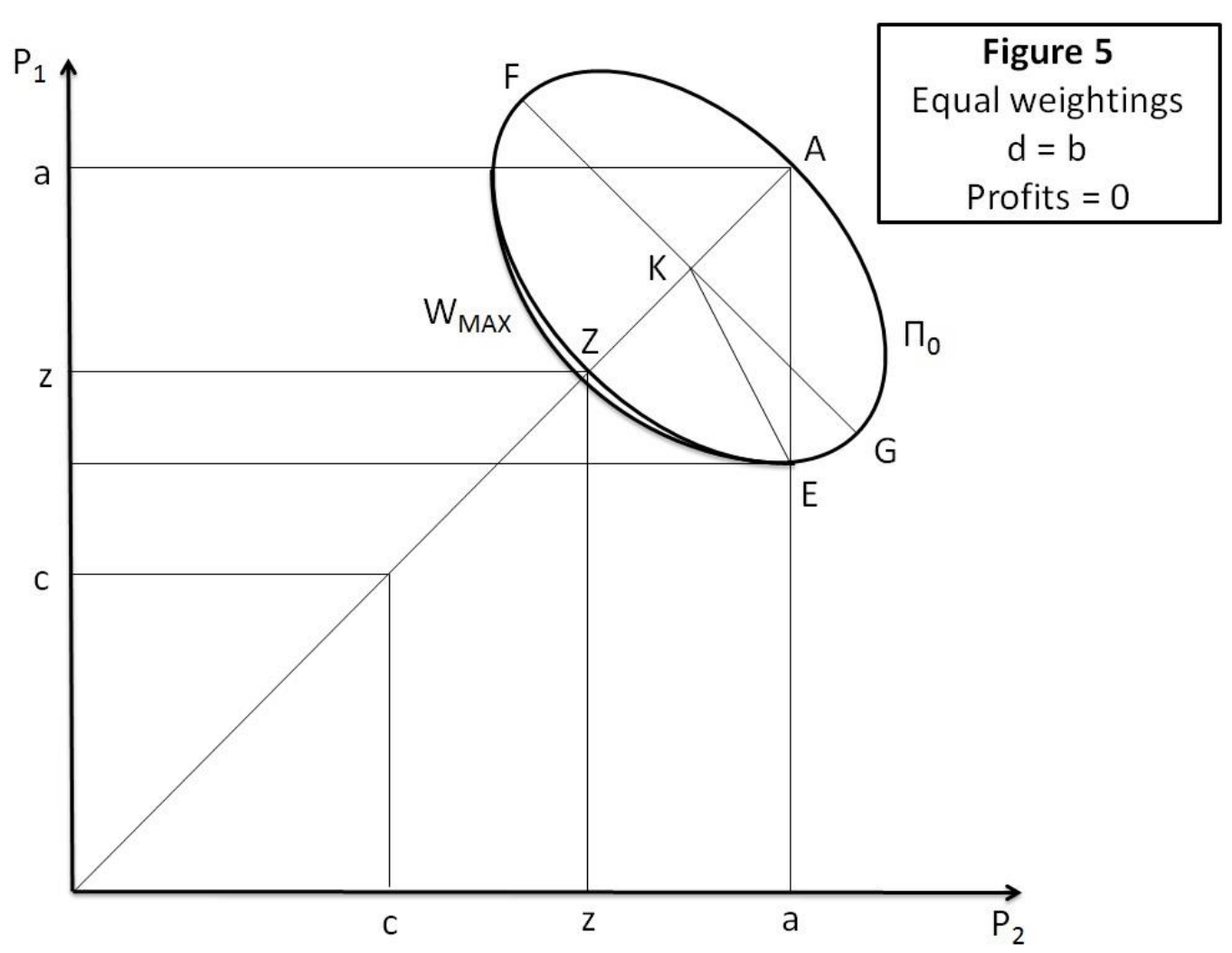

Using the expressions derived around equation (10) in Section 3, in this case the values of $z$ and $k$ are $(2 a+c) / 3$ and $(5 a+c) / 6$. It is useful to adopt the following notation:

$$
g=\frac{a-c}{6}=\frac{f}{3}
$$

This means that the distances $A K, A Z$ and $A E$ take the values $\sqrt{ } 2 g, 2 \sqrt{ } 2 g$ and $3 g$ respectively. Where there is no intervention, the outcome is at $K$ and, using equation 
(15), the consumer surplus is $g^{2} / b$. Where the tariff is introduced with the same value in both markets, the outcome is at $z$ and the consumer surplus equals $4 g^{2} / d$. As in the case where $d=0$, introducing the uniform minimum tariff increases consumer surplus to 4 times its original value. However, if the minimum tariff is only imposed in one market, in this case the consumer surplus is given as $9 g^{2} / 2 b$. This gives a higher value than either of the other options. Of course, this implies that if the consumer surplus in market 1 were given a greater weight than those in market 2 , this would furnish an even stronger argument for favouring the introduction of a single tariff in only that market.

We know that for $d \geq b$, then the zero profit outcome means setting price equal to the wholesale price in market 1 . In that case the consumer surplus, $\bar{S}_{T}^{1}$, is given as:

$$
\bar{S}_{1}=\frac{b}{2}\left[\frac{a-c}{b+d}\right]^{2}
$$

However, the consumer surplus where the tariff is introduced in both markets simultaneously, $\overline{S_{2}}$, equals:

$$
\bar{S}_{T}^{2}=b\left[\frac{a-c}{b+2 d}\right]^{2}
$$

For $\bar{S}_{T}^{1} \geq \bar{S}_{T}^{2}$, then $d>\frac{b}{\sqrt{2}}$. But where market 2 is reduced to an output of zero, then $d \geq b>\frac{b}{\sqrt{2}}$, so that wherever this occurs, the choice between equal minimum tariffs in both markets and concentrating in just one market means that the consumer surplus would be maximised by just applying the tariff to one market. ${ }^{13}$

\footnotetext{
${ }^{13}$ This also means that there is a range of values for $d$ given by $\frac{b}{\sqrt{2}} \leq d \leq b$ where a greater consumer surplus would be generated, with a zero profit constraint, by setting a tariff in market 1 equal to the average wholesale price and a tariff higher than the marginal wholesale cost in the second market, rather than a common tariff in both markets.
} 
In the section we consider the impact of the wholesale price being positively related to total output, implying that the price in one market is affected by the output in the other market. This increases the consumer welfare benefit of a tariff in just one market, as against a uniform tariff in both.

\section{Conclusions}

It is often the case that in regulated markets with a degree of monopoly power price controls are imposed in only one segment of the market. Examples in the UK apply in the retail electricity, rail transport, education and housing markets. This behaviour is typically motivated by redistributive considerations, with the welfare of one set of consumers weighted more heavily than others. In the case of the electricity market this could be motivated by concerns over affordability.

The decision not to set differential tariffs that cover the whole of the market might reflect administrative or presentational considerations. On the administrative side, the regulator might lack the information required to set or impose all prices. Concerning presentation, the government might simply wish to affirm a continuing general commitment to market mechanisms or to avoid responsibility for the potentially higher prices that redistributive regulation implies for some segments of the market. In this paper we formally analyse this behaviour using a very stylised model in which a monopolist serving two separate retail markets is a monopsonist in an otherwise competitive wholesale market. The paper focuses on the consumer welfare implications of imposing a price tariff in only one market, against having to impose a uniform tariff in both markets.

The analytical results suggest that the welfare costs of imposing price constraints in only one market are relatively low, and this is especially the case where the benefits to the favoured market are weighted more heavily. Where the minimum profit constraint is increased, the relative welfare loss from price control only operating in one market 
is further reduced. Moreover, with a degree of scarcity in the wholesale market we get the potential for a counterintuitive result. This is that there are conditions where it is better to only control one tariff, rather than impose a uniform tariff in both markets, even with neutral consumer welfare weights.

It is important to stress the theoretical nature of this analysis. There are a number of issues which need to be addressed if price tariffs are imposed. For example, there are practical questions as to whether it is appropriate to use price discrimination to tackle affordability problems. In particular, it is necessary to be able to identify, separate and properly target the individual markets. Where this targeting is imperfect, some low income consumers will be subject to inappropriately high prices. A second set of concerns center around the effect that price controls could have on competition and potential new entry. In future research we are particularly interested in analyzing the effect of price controls on potential future entry and competition, the impact of differential retail market characteristics within the model and the problems raised by incomplete or asymmetric information on the part of firms and the regulator. 


\section{References}

Armstrong, M. (2008), Price Discrimination in P. Buccirossi, ed., Handbook of Antitrust Economics, pp. 433-467, Cambridge, Massachusetts, MIT Press.

Braeutigam, R.R., Panzar, J.C., 1993. Effects of the Change from Rate-of-Return to Price-Cap Regulation. The American Economic Review, Vol. 83, No. 2, pp. 191-198.

Brown, D. P., Eckert, A., Eckert, H., 2017. Electricity markets in transition: Market distortions associated with retail price controls. The Electricity Journal, Vol. 30, pp. 3237.

Butcher, L. (2017), Rail Fares and Ticketing, Commons Briefing Paper SNO 1904, House of Commons Library

Cowan, S., 2002. Price-cap regulation. Swedish Economic Policy review, Vol. 9, pp. Department for Business, Energy and Industrial Strategy (2017), Annual Fuel Poverty Statistics Report, 2017 (2015 Data), London.

Dobbs, I.M., 2004. Intertemporal price cap regulation under uncertainty. The Economic Journal, 114, pp. 421-440.

Felder, F.A., 2010, The Practical Equity Implications of Advanced Metering Infrastructure. The Electricity Journal, Vol. 23, No. 6, pp. 56-64.

HM Treasury, 2003. The Green Book: Appraisal and Evaluation in Central Government. Treasury Guidance, London, TSO.

Hviid, M., Waddams Price, C., 2012. Non-Discrimination clauses in the retail energy sector. The Economic Journal, Vol. 122, pp. F236-F252.

Joskow, P., 2005. Regulation and Deregulation after 25 Years: Lessons Learned for Research in Industrial Organisation. Review of Industrial Organization, Vol. 26, pp. 169-193.

Joskow, P., Tirole, J., 2000. Transmission Rights and Market Power on Electric Power Networks. The RAND Journal of Economics, Vol. 31, No. 3, pp. 450-487. Joskow, P., Tirole, J., 2006. Retail electricity competition. The RAND Journal of Economics, Vol. 37, No. 4, pp. 799-815.Kang, J., Weisman, D.L., Zhang, M., 2000. Do consumers benefit from tighter price cap regulation?. Economic Letters, Vol. 67, pp. 113-119. 
Kennedy, P. W., 1994. Equilibrium Pollution Taxes in Open Economies with Imperfect Competition. Journal of Environmental Economics and Management, Vol. 27, pp. 49-63.

Littlechild, S., 2014. Promoting or restricting competition?: Regulation of the UK residential energy market since 2008. EPRG Working Paper 1415, Cambridge Working Paper in Economics. Available at: http://www.eprg.group.cam.ac.uk/wpcontent/uploads/2014/09/1415-PDF.pdf

Littlechild, S., 2016. The CMA energy market investigation, the well-functioning market, Ofgem, Government and behavioural economics. Available at: https://assets.publishing.service.gov.uk/media/56b9d951e5274a0369000015/Mr_Step hen_Littlechild_submission_February_2016.pdf

Littlechild, S., 2017. Competition and Price Controls in the UK Retail Energy Market. Network, Issue 63, A publication of the Australian Competition and Consumer Commission for the Utility Regulators Forum. Available at: https://www.acc..gov.au/system/files/network\%20june\%202017\%20\%28D201700045379\%29.pdf

Ofgem, 2016. Retail Energy Markets in 2016. Published 3 August 2016. Available at: https://www.ofgem.gov.uk/system/files/docs/2016/08/retail_energy_markets_in_2016 . $\mathrm{pdf}$

Ofgem, 2017. Prepayment price cap: 1 October 2017 to 31 March 2018. Published $7^{\text {th }}$ August 2017. Available at: https://www.ofgem.gov.uk/publications-andupdates/prepayment-price-cap-1-october-2017-31-march-2018

Parker, D., 1997. Price cap regulation, profitability and returns to investors in the UK regulated industries. Utilities Policy, Vol. 6, No. 4, pp. 303-315.

Scottish Government (2015), Scotland's Economic Strategy, March 2015, Scottish Government, Edinburgh.

Simshauser, P., 2014. When Does Electricity Price Cap regulation Become Distortionary?. The Australian Economic Review, Vol. 47, No. 3, pp. 304-323. 
Simshauser, P., Nelson, T. 2014. The Consequences of Retail Electricity Price Rises: Rethinking Customer Hardship. The Australian Economic review, Vol. 47, No. 1, pp. $13-43$

Simshauser, P., Whish-Wilson, P., 2017. Price discrimination in Australia's retail electricity markets: An Analysis of Victoria \& Southeast Queensland. Energy Economics, Vol. 62, pp. 92-103.

Stole, L. (2007), Price Discrimination and Competition in M. Armstrong and R. Porter, eds., Handbook of Industrial Economics, vol. III, pp. 221-299, Amsterdam, Elsevier.

Ulph, A., 1996. Environmental policy and International trade when Governments and Producers Act Strategically. Journal of Environmental Economics and Management, Vol. 30, pp. 265-281.

Waddams Price, C., 2005. The Effect of Liberalizing UK Retail Energy Markets on Consumers. Oxford Review of Economic Policy, Vol. 21, No. 1, pp. 128-144. 


\section{Appendix A: Unconstrained profit maximisation}

Using the first order conditions, in the case with no regulation, the unconstrained profitmaximizing outputs in markets one and two are given as:

$$
q_{i}^{U}=\frac{a-c}{2(b+2 d)} \quad i=1,2
$$

These quantities are positive as long as production is financially viable at all (that is as long as $a>c$ ). The corresponding prices in the individual markets can be obtained from substituting equation (A1) into equation (1) in the text. This gives:

$$
p_{i}^{U}=\frac{4 a d+a b+b c}{2(b+2 d)}
$$

In the specific unconstrained case, substituting equations (3), (A1) and (A2) into equation (5) produces, with some manipulation:

$$
\Pi_{T}^{U}=\frac{(a-c)^{2}}{2(b+2 d)}-\Gamma
$$

In the short run, production is profitable as long as $a>c$. In the long run, revenue needs to be enough to cover the fixed costs, $\Gamma$, in order that non-negative profits can be made. Each market makes half of the revenue, so that the short-run profits made in each market, $\Pi_{i}^{U}$, can be identified as:

$$
\Pi_{i}^{U}=\frac{(a-c)^{2}}{4(b+2 d)}
$$

This gives the current profit in each market but does not allocate the fixed costs across markets.

\section{Appendix B: Allowing the demand parameters to differ.}


If the market demand parameters are allowed to differ, equation (1) in the text becomes:

$$
p_{i}=a_{i}-b_{i} q_{i} \quad i=1,2
$$

To illustrate the implications, we taking the most straightforward case where the consumption weights are equal and the wholesale price does not vary with scale, so that $\omega_{1}=\omega_{2}=1$ and $d=0$. Fixing the consumers' welfare at a positive level, $\bar{S}_{T}$, produces the iso-welfare function for the tariff values $\bar{p}_{1} \leq a_{1}, \bar{p}_{2} \leq a_{2}$ as:

(A6) $\bar{S}_{T}=\frac{1}{2 b_{1}}\left(a_{1}-\bar{p}_{1}\right)^{2}+\frac{1}{2 b_{2}}\left(a_{2}-\bar{p}_{2}\right)^{2}$

where:

$$
\frac{\partial S_{T}}{\partial \bar{p}_{i}}=-\frac{\left(a_{i}-\bar{p}_{i}\right)}{b_{i}} \leq 0
$$

Each iso-welfare function is here the segment of an elipse which is centred at the point $\left(a_{1}, a_{2}\right)$ in $\bar{p}_{1}, \bar{p}_{2}$ space. Consumer welfare is minimized, that is takes a zero value, where $\bar{p}_{1}=a_{1}, \bar{p}_{2}=a_{2}$. In general the slope of the iso-consumer's welfare function is given as:

$$
\frac{d \bar{p}_{1}}{d \bar{p}_{2}}=\frac{-\partial S_{T} / \partial \bar{p}_{2}}{\partial S_{T} / \partial \bar{p}_{1}}=-\frac{b_{1}\left(a_{2}-\bar{p}_{2}\right)}{b_{2}\left(a_{1}-\bar{p}_{1}\right)}
$$

All the iso-welfare functions are vertical where $\bar{p}_{1}=a_{1}$ and horizontal where $\bar{p}_{2}=a_{2}$. They have the general form of the weighted iso-welfare functions identified by equation (6) in the text.

Total profits are given as:

(A8) $\Pi_{T}=\sum_{i} \frac{\left(\bar{p}_{i}-c\right)\left(a_{i}-\bar{p}_{i}\right)}{b_{i}}$

This implies that 
(A9) $\frac{\partial \Pi_{T}}{\partial \bar{p}_{i}}=\frac{\left(a_{i}+c\right)-2 \bar{p}_{i}}{b_{i}}, \frac{\partial^{2} \Pi_{T}}{\partial\left(\bar{p}_{i}\right)^{2}}=-\frac{2}{b_{i}}<0$

Again for a given profit level, $\bar{\Pi}_{T}$, equation (A8) can be used to define the corresponding iso-profit function as:

(A10) $b_{2}\left[\bar{p}_{1}-\left[\frac{a_{1}+c}{2}\right]\right]^{2}+b_{2}\left[\bar{p}_{2}-\left[\frac{a_{2}+c}{2}\right]\right]^{2}=\frac{b_{1}\left(a_{1}-c\right)^{2}+b_{2}\left(a_{2}-c\right)^{2}}{2}-b_{1} b_{2} \Pi_{T}$

The slope of the iso-profit curve, is given as:

(A11) $\frac{d \bar{p}_{1}}{d \bar{p}_{2}}=\frac{-\partial \Pi_{T} / \partial \bar{p}_{2}}{\partial \Pi_{T} / \partial \bar{p}_{1}}=-\frac{b_{2}\left(a_{2}+c-2 \bar{p}_{2}\right)}{b_{1}\left(a_{1}+c-2 \bar{p}_{2}\right)}$

The iso-profit curve is horizontal and vertical where $\bar{p}_{2}=\frac{a_{2}+c}{2}$ and $\bar{p}_{1}=\frac{a_{1}+c}{2}$ respectively. The iso-profit curve is therefore an elipse whose center is $\left(\frac{a_{1}+c}{2}, \frac{a_{2}+c}{2}\right)$ in $\bar{p}_{1}, \bar{p}_{2}$ space.

The subsequent diagrammatic analysis follows that in the text but clearly the implications and interpretation of the impact of changes in these parameter values requires extended and more detailed investigation. 